\title{
Long-term Prognosis of Localized Lymphoid Hyperplasia of the Rectum
}

\author{
Ji Taek Hong ${ }^{1}$, Eun Ran Kim², Sung-Wook Park², Ji Won Kim², Sung Noh Hong², Dong Kyung Chang², Young-Ho \\ $\mathrm{Kim}^{2}$, and Jun Hun $\mathrm{Cho}^{3}$ \\ ${ }^{1}$ Department of Internal Medicine, Hallym University College of Medicine, Chuncheon, Departments of ${ }^{2}$ Medicine and ${ }^{3}$ Pathology, \\ Samsung Medical Center, Sungkyunkwan University School of Medicine, Seoul, Korea
}

\section{Article Info}

Received August 19, 2019

Revised November 30, 2019

Accepted December 6, 2019

Published online February 18, 2020

\section{Corresponding Author}

Eun Ran Kim

ORCID https://orcid.org/0000-0002-0495-2565

E-mail er.kim@samsung.com
Background/Aims: Although localized lymphoid hyperplasia (LLH) of the rectum is occasionally observed, its clinical implications are unclear. This study aimed to investigate the clinical course and significance of LLH of the rectum.

Methods: We identified 65 patients diagnosed with LLH of the rectum using a histopathologic examination and who received follow-up endoscopies between January 2009 and June 2015. Patients with a history of inflammatory bowel disease, lymphoma, familial adenomatous polyposis, or uncontrolled malignancy and patients who underwent scar biopsy after endoscopic resection or surgery were excluded. Endoscopic findings and clinical courses were analyzed.

Results: During the median follow-up of 31 months (interquartile range, 19 to 40 months), $81.5 \%$ (53/65) of LLHs of the rectum were resolved. Clinically significant diseases, including ulcerative colitis (UC, $n=5)$ and mucosa-associated lymphoid tissue (MALT) lymphoma $(n=1)$, were diagnosed in $9.2 \%$ of patients $(6 / 65)$. The other six patients showed no significant changes in the lesion $(n=3)$ or a waxing and waning appearance $(n=3)$. According to endoscopic findings, all of the 47 polypoid types showed resolution or waxing and waning patterns. Five of the 11 nodular types (45.5\%) developed into UC. One of the seven submucosal tumor (SMT)-like types (14.3\%) developed into MALT lymphoma.

Conclusions: LLH of the rectum with persistent symptoms or the endoscopic appearance of the nodular or SMT-like type may lead to clinically significant disease. Risk stratification according to endoscopic findings and careful surveillance are required for these lesions. (Gut Liver 2021;15:77-84)

Key Words: Lymphoid hyperplasia; Rectum; Colitis, ulcerative; Mucosa-associated lymphoid tissue lymphoma
INTRODUCTION

Localized lymphoid hyperplasia (LLH) of the colon appears almost exclusively in the rectum. ${ }^{1,2}$ This lesion is also known as lymphoid polyp, benign lymphoid polyp, or rectal tonsil. ${ }^{2-5}$ Histologically, LLH consists a dense lymphoid infiltrate in the lamina propria and submucosa characterized by follicles with well-formed germinal centers varying in size, often being strikingly enlarged with a narrow surrounding mantle zone. ${ }^{6}$ Despite lymphoid hyperplasia being generally benign, it is known to be associated with multiple diseases, including inflammatory bowel disease, different infections, and colonic carcinoma. ${ }^{7,8}$ There are also some reports that the lesion can be a risk factor for intestinal lymphoma or, very rarely, for extraintestinal lymphoma. ${ }^{9-20}$ Therefore, since lymphoid hyperplasia may indicate risks for lymphoma, some researchers recommend surveillance of the lesion. ${ }^{21}$ However, no guideline has been established for the follow-up and management on the lesion. Moreover, despite its asymptomatic nature, nodular lymphoid hyperplasia may lead to gastrointestinal symptoms, including abdominal pain, chronic diarrhea, bleeding, or intestinal obstruction. ${ }^{22-24}$ In addition, LLH of the rectum may represent differently on endoscopic appearances. LLH can not only appear as a sessile polyp, varying in size (usually $<40 \mathrm{~mm}$ ), but also as a mass. ${ }^{6,25-29}$ 
Thus, although these lesions may sometimes cause symptoms or endoscopically appear in various forms, their clinical course in relation to endoscopic features or symptoms remains uncertain. Therefore, we analyzed the endoscopic findings and clinical course of LLH of the rectum to determine the clinical significance of the lesions.

\section{MATERIALS AND METHODS}

\section{Patients}

We carried out a retrospective cohort study, analyzing medical records including endoscopic and pathologic reports of patients who underwent endoscopy at the Samsung Medical Center from January 2009 to June 2015. During this period, 212,188 colonoscopic and sigmoidoscopic examinations were performed, and 390 patients were identified as having been diagnosed with LLH of the rectum in the first endoscopy, receiving one or more follow-up endoscopies. In these patients, those with the following conditions that could confound interpretation were excluded: (1) those with a history of inflammatory bowel disease, lymphoma, familial adenomatous polyposis, metastatic malignancy, or uncontrolled rectal cancer; (2) those who underwent histopathologic examination with a post-polypectomy scar or postoperative scar; (3) those who displayed endoscopic appearance of simple erosion or hyperemia; and (4) those under 20 years of age. As a result, 65 patients were included and reviewed for clinical courses and surveillance endoscopic findings (Fig. 1). Two authors (S.W.P. and J.W.K.), who were blinded to the clinical course, independently classified endoscopic findings of the lesions based on endoscopic images and investigated the pattern changes in endoscopic appearance. The study protocol was approved by the Institutional Review Board of Samsung Medical Center (IRB number: SMC 201901-002-001). The requirement for patient's consent was waived given the retrospective nature of the study.

\section{Definition}

Based on endoscopic appearance, patients were divided into three groups: polypoid type, nodular type, and submucosal tumor (SMT)-like type. ${ }^{6,25-29}$ The polypoid type was defined as one or more growths protruding from a mucous membrane, the nodular type as profuse/dense distribution of knot-like protuberances that are 2 to $3 \mathrm{~mm}$ in diameter, and the SMT-like type as a protruding lesion covered with normal-appearing mucosa.

LLH was defined as a polyp, multiple nodules, or a protruding lesion diagnosed with hyperplasic lymphoid follicles, mitotically active germinal centers with well-defined lymphocytes mantles, and lymphoid follicles localized in the mucosa and/or submucosa identified on pathological examination. $^{9}$

\section{Statistical analysis}

Statistical analyses were performed using a statistical software package SPSS 12.0 for Windows (SPSS Inc., Chicago, IL, USA). When appropriate, results were expressed as proportions, mean \pm standard deviation, or medians (interquartile range, IQR). Significance was evaluated using the Fisher exact test, independent t-test, Mann-Whitney U-test, and Kruskal-Wallis test. A p $<0.05$ was considered statistically signficant.
212,188 Participants who underwent colonoscopy or sigmoidoscopy between January 2009 and June 2015

390 Participants who diagnosed with LLH of rectum and underwent follow-up endoscopies
Fig. 1. Flowchart of the recruitment of patients from the study population.

LLH, localized lymphoid hyperplasia; MALT, mucosa-associated lymphoid tissue. *Endoscopic appearance of simple erosion or hyperemia. 


\section{RESULTS}

\section{Baseline characteristics}

The 65 patients consisted of 41 men and 24 women with a mean age of $57.8 \pm 13.3$ years. The indications for endoscopy included screening of colorectal neoplasia in 18 patients (27.7\%), surveillance of past colorectal neoplasia in $18(27.7 \%)$, endoscopic resection of colorectal neoplasia in $13(20 \%)$, preoperative or pre-radiation evaluation in seven (10.8\%), blood tinged stool or positive result of fecal occult blood test in four (6.1\%), and other miscellaneous screenings in five (7.7\%). Endoscopic appearances of LLHs of the rectum are shown in Fig. 2. The polypoid type was most common ( $n=47,72.3 \%)$, followed by the nodular type $(\mathrm{n}=11,16.9 \%)$ and the SMT-like type $(\mathrm{n}=7,10.8 \%)$. There was no significant difference in the follow-up period, monitoring interval, and frequency of follow-up among all groups (Supplementary Table 1).

\section{Clinical outcomes}

Clinical course and follow-up endoscopic findings of the 65 patients are presented in Fig. 3. The median duration of follow-up was 31 months (IQR, 19 to 40.1 months). The median number of follow-up endoscopy was 2 (IQR, 1 to 3 ), and the median interval between endoscopies was 13.3 months (IQR, 9.6 to 23.8 months). In 54 of the 65 patients, LLHs of the rectum were seen to be resolved at the first follow-up endoscopy. Twenty-nine of these 54 patients received subsequent follow-up endoscopy ( 25 of whom remained to be resolved), three had recurrence of LLH, and one had progression to extranodal marginal zone Bcell lymphoma mucosa-associated lymphoid tissue (MALT)
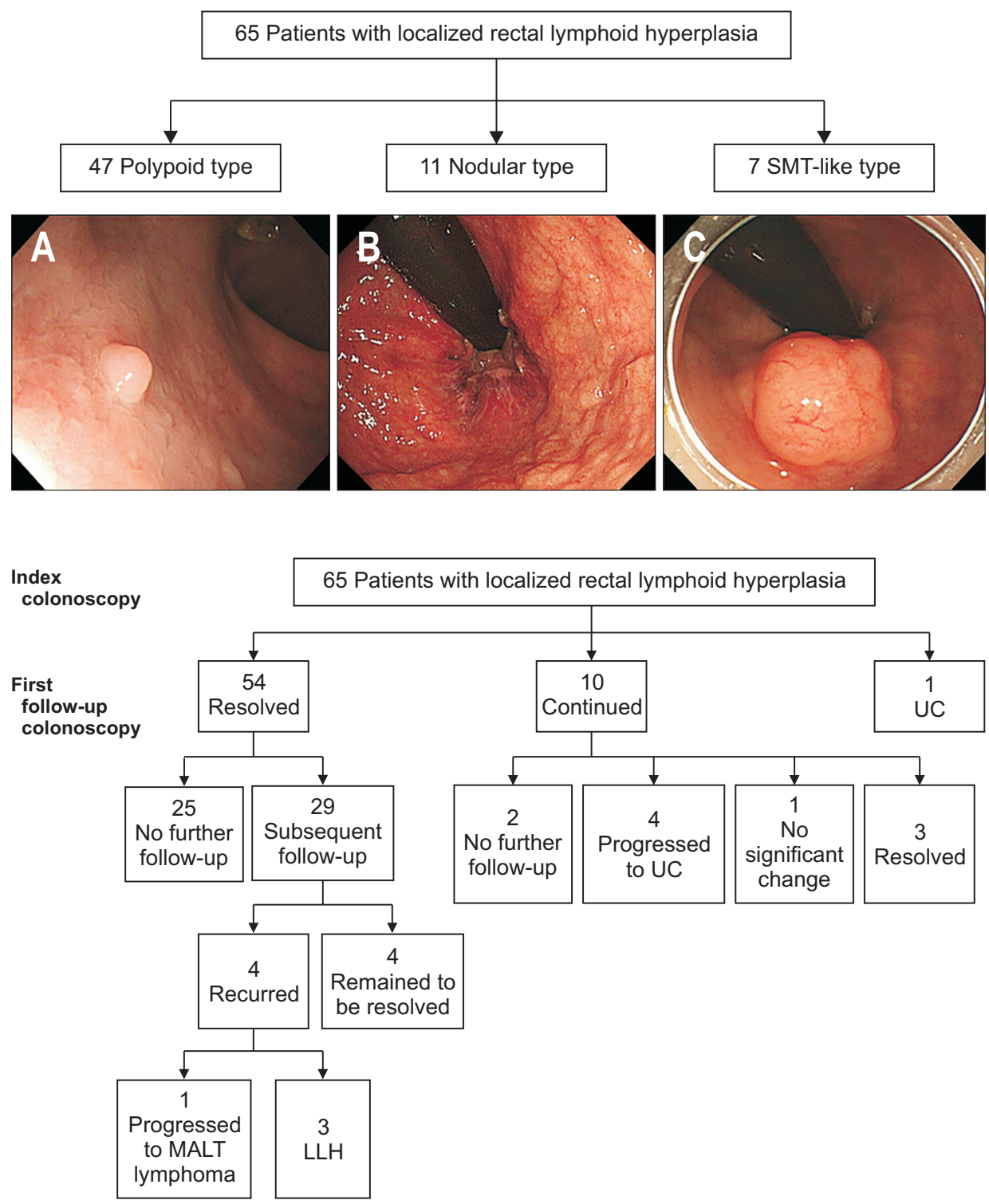

Fig. 2. Classification of localized lymphoid hyperplasia of the rectum. (A) Polypoid type, (B) nodular type, and (C) submucosal tumor (SMT)-like type.
Fig. 3. Flowchart of follow-up endoscopies and clinical courses.

UC, ulcerative colitis; MALT, mucosa-associated lymphoid tissue; LLH, localized lymphoid hyperplasia. 
type. In 10 of the 65 patients, LLHs were present in the follow-up endoscopy. Eight of these 10 patients received subsequent follow-up endoscopy. Of these eight, three had lesions resolved, one remained with no significant change, and the other four progressed to ulcerative colitis (UC). The other one of the 65 patients was diagnosed with UC in the first follow-up colonoscopy. In five patients with confirmed UC, the median duration was 14.6 months (range, 6.3 to 16 months) from LLH diagnosis to UC. One patient diagnosed with MALT lymphoma took 17 months from the first diagnosis of LLH.

Clinical outcomes based on endoscopic findings are presented in Fig. 4. All of the 47 polypoid type LLHs showed resolution or waxing and waning patterns. Of the 11 nodular types, five $(45.5 \%)$ developed UC, and of the seven SMT-like types, one (14.3\%) developed MALT lymphoma (Figs 5 and 6).

Endoscopic findings and clinical features of patients according to significant disease are presented in Table 1. Comparing the two groups based on endoscopic appear- ance, the proportion of nodular type was higher in the group of patients with significant disease, showing a statistically significant difference.

In LLHs of patients with significant disease, the proportion of patients who received endoscopy due to symptoms $(3 / 6,50 \%)$ was higher than that for LLHs of patients with a benign course $(3 / 59,5 \%)(\mathrm{p}=0.008)$. LLHs were also resolved in $90 \%(36 / 40)$ of asymptomatic patients who received endoscopy for screening or surveillance for a past disease.

\section{DISCUSSION}

We found that $81.5 \%(53 / 65)$ of LLHs of the rectum resolved during the median follow-up of 31.2 months, and clinically significant diseases were confirmed in 9.2\% (6/65) of patients with LLH. The other six patients showed no interval change or waxing and waning appearance. LLHs of patients with significant disease were either the nodular
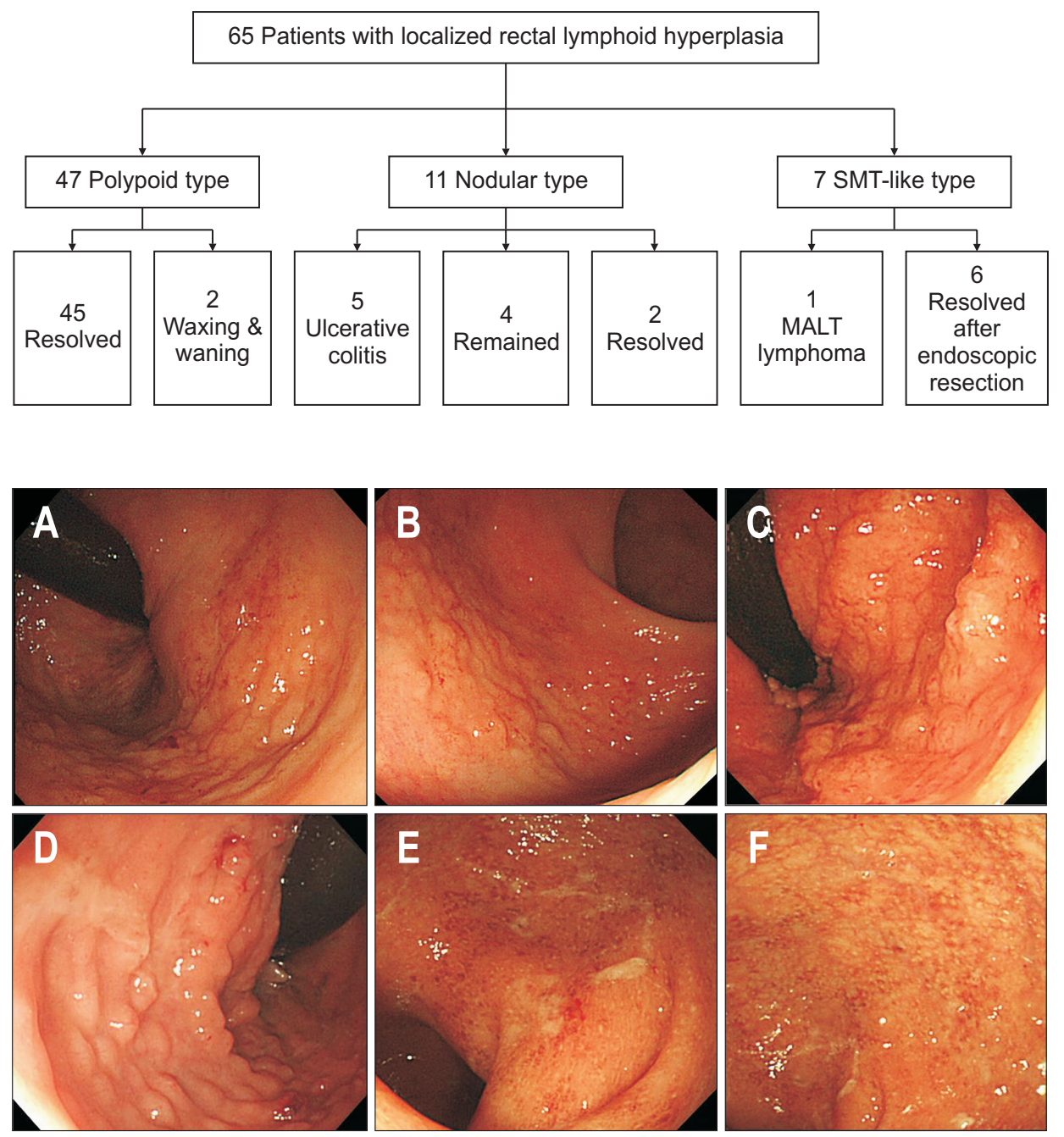

Fig. 4. Clinical courses according to endoscopic appearance. SMT, submucosal tumor; MALT, mucosa-associated lymphoid tissue.
Fig. 5. Endoscopic images in patients diagnosed with inflammatory bowel disease (IBD). (A-D) Endoscopic images of localized lymphoid hyperplasia before IBD diagnosis. (E, F) Endoscopic images at the time of IBD diagnosis. 

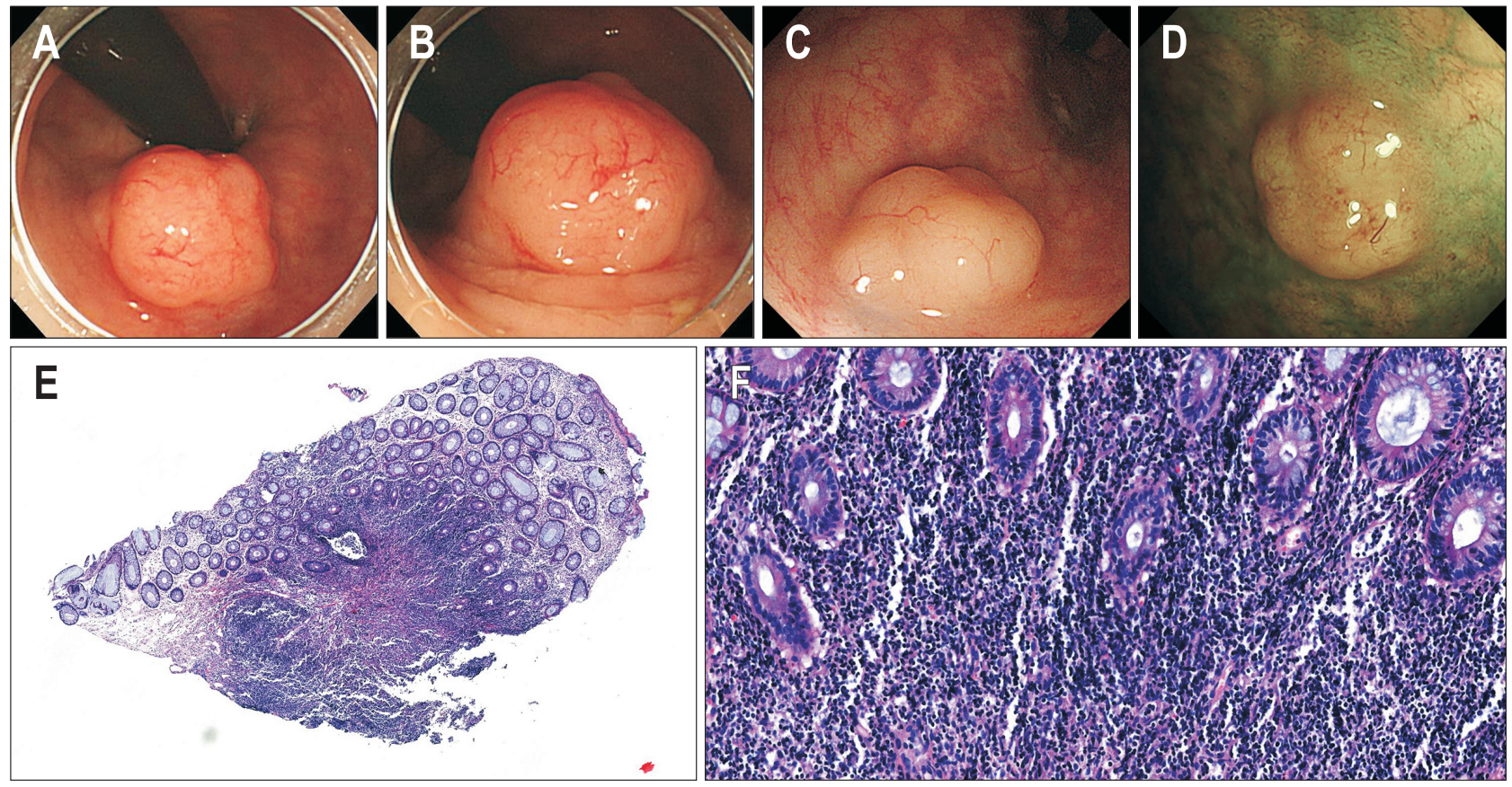

Fig. 6. Endoscopic and pathologic images in patients diagnosed with mucosa-associated lymphoid tissue (MALT) lymphoma. (A, B) Endoscopic images of localized lymphoid hyperplasia before MALT lymphoma diagnosis and (C, D) endoscopic images at the time of MALT lymphoma diagnosis. Histopathological findings of MALT lymphoma. (E) Dense lymphocytic infiltration in lamina propria without lymphoid follicles (H\&E, scan view) and (F) dense small lymphocytic infiltration in lamina propria with no definite lymphoepithelial lesion $(H \& E, \times 100)$.

Table 1. Characteristics of Patients According to Significant Disease

\begin{tabular}{|c|c|c|c|c|}
\hline Characteristic & Patients without significant disease $(n=59)$ & Patients with significant disease $(n=6)$ & $t^{*} / Z^{+}$ & p-value \\
\hline Age, yr & $59.2 \pm 12.3$ & $44.7 \pm 16.3$ & $2.67 *$ & $<0.01$ \\
\hline Male sex & 40 (67.8) & $1(16.7)$ & & 0.02 \\
\hline Duration of follow-up, day & $913.9 \pm 500.3$ & $1,146.8 \pm 989.4$ & $-0.57^{*}$ & 0.59 \\
\hline Interval of follow-up, day & $543.9 \pm 350.6$ & $301.7 \pm 105.6$ & $-1.84^{\dagger}$ & 0.07 \\
\hline No. of endoscopies & $1.9 \pm 1.1$ & $3.3 \pm 2.0$ & $-1.93^{\dagger}$ & 0.07 \\
\hline Endoscopic appearance & & & & $<0.01^{\ddagger}$ \\
\hline Polypoid type & $47(79.7)$ & 0 & & \\
\hline Nodular type & $6(10.2)$ & 5 (83.3) & & \\
\hline SMT-like type & $6(10.2)$ & $1(16.7)$ & & \\
\hline Size, $\mathrm{mm}$ & & & & $0.21^{\ddagger}$ \\
\hline$<6$ & 54 (91.5) & $5(83.3)$ & & \\
\hline $6-15$ & $4(6.8)$ & 0 & & \\
\hline$\geq 15$ & $1(1.7)$ & $1(16.7)$ & & \\
\hline
\end{tabular}

Data are presented as mean \pm SD or number $(\%)$.

SMT, submucosal tumor.

*Independent t-test; ${ }^{\dagger}$ Mann-Whitney U-test; ${ }^{\ddagger}$ Fisher exact test.

type or the SMT-like type, and the proportion of nodular type and patients who received endoscopy due to symptoms was higher than that of LLHs of patients with a benign course. LLHs resolved in most asymptomatic patients who received endoscopy for screening or surveillance for a past disease $(90 \%, 36 / 40)$. Endoscopic findings and clinical features of patients with advanced disease are presented in Table 2.

As the demand for screening and surveillance of colorec- tal neoplasms increases, the diagnosis of LLH of the rectum is becoming more frequent in clinical practice. However, the clinical significance of pathological findings such as lymphoid aggregates, lymphoid follicles, and lymphoid hyperplasia is ambiguous, and it is difficult to determine whether follow-up is necessary or whether advanced diseases such as lymphoma should be differentiated. To the best of our knowledge, there are only a few case series in the literature reporting LLH of the rectum. 
In a case series, Farris et al. ${ }^{25}$ reported that there was no recurrence during the mean follow-up period of 5.8 years among 11 endoscopically resected LLHs of the rectum, mimicking lymphoma. In another case series regarding histological variety of the LLHs, Kojima et al..$^{30}$ reported that there was no evidence of transformation to malignant lymphoma during the mean follow-up period of 1.38 years. Focusing on histological analysis, these studies showed that LLHs of the rectum had a benign clinical course, despite the endoscopic appearances of advanced disease. However, these reports had common limitations that only a few cases were included and the inclusion criteria and follow-up methodology were not clearly presented. Conversely, our study demonstrated a natural progression and clinical course of LLH of the rectum by analyzing a largescale medical database with careful exclusions to reduce confounding factors.

Inflammatory bowel disease, including UC and Crohn's disease, is a debilitating disorder of the gastrointestinal tract, characterized by a dysregulated immune response to unknown environmental triggers. ${ }^{31}$ The persistent underlying inflammatory reaction may have been observed with endoscopic appearances of lymphoid hyperplasia. There has been a lack of research on the progression of endoscopic features in patients with UC. Our results suggest that LLHs of the rectum may be an early form of UC, especially proctitis.

Despite the rising incidence and prevalence of UC in Asian countries, it is still lower than those in the West. ${ }^{32,33}$ From this point of view, the proportion of patients with LLH with progression to UC is considered to be high in this study. A potential explanation for this discrepancy is the relatively high number of patients who underwent endoscopy due to hematochezia or positive results of fecal occult blood test. In addition, the inclusion criteria for pa- tients who received more than two endoscopies may have served as a selection bias to select more patients with clinically significant disease.

Although some studies have reported LLH of the rectum that mimic MALT lymphoma, LLH has the following distinctive histological features from MALT lymphoma: proliferation of normal lymphoid tissue, which has a prominent follicular pattern and a clearly defined germinal center that varies in size, often being strikingly enlarged with a narrow surrounding mantle zone. ${ }^{22,25}$ Immunohistochemical and molecular examinations also help to differentiate LLH from a malignant condition. ${ }^{6,27,34}$ Unlike previous reports, our results suggest that the risk of MALT lymphoma may exist in patients who have undergone endoscopic resection of SMT-like type LLH.

There are several limitations to the present study. First, our study has a retrospective design with the potential for selection bias. We tried to minimize the effects of confounding factors by the careful inclusion and exclusion of cases. However, as many cases were excluded from the analysis, the possibility of a selection bias increased. Second, several endoscopists and pathologists participated in obtaining endoscopic images and pathologic findings because of the long duration of the study. This may have resulted in interobserver variation. Third, some patients were not followed-up at regular intervals because the patients whose endoscopic indications were screenings and diagnostic examinations were included in the analysis. This may have influenced the natural progression of LLH to be underestimated or overestimated. Fourth, this research is based on a modest sample size. To date, however, this study has included the largest group of patients diagnosed with LLH of the rectum to evaluate the clinical course and significance of these lesions. The median follow-up period was 31 months (IQR, 19 to 40.1 months) in the present

Table 2. Endoscopic Findings and Clinical Features of Patients with Advanced Disease

\begin{tabular}{|c|c|c|c|c|c|c|c|}
\hline No. & $\begin{array}{c}\text { Final } \\
\text { diagnosis }\end{array}$ & $\begin{array}{l}\text { Endoscopic } \\
\text { finding }\end{array}$ & $\begin{array}{l}\text { Age } \\
\text { (yr) }\end{array}$ & Sex & Indication & $\begin{array}{l}\text { Duration between diagnosis of } \\
\text { LLH and advanced disease (mo) }\end{array}$ & Initial pathologic diagnosis \\
\hline 1 & UC & Nodular type & 50 & Male & Screening & 12 & Lymphoid follicle \\
\hline 2 & UC & Nodular type & 39 & Female & FOBT (+) & 15 & Lymphoid follicle \\
\hline 3 & UC & Nodular type & 56 & Female & Blood tinged stool & 14.6 & $\begin{array}{l}\text { Diffuse active inflamma- } \\
\text { tion with focal cryptitis and } \\
\text { lymphoid aggregates }\end{array}$ \\
\hline 4 & UC & Nodular type & 27 & Female & Hematochezia & 16 & Lymphoid follicle \\
\hline 5 & UC & Nodular type & 28 & Female & Blood tinged stool & 6.3 & $\begin{array}{l}\text { Focal active inflammation } \\
\text { with cryptitis and lymphoid } \\
\text { aggregates }\end{array}$ \\
\hline 6 & $\begin{array}{l}\text { MALT } \\
\text { lymphoma }\end{array}$ & SMT-like type & 68 & Female & $\begin{array}{l}\text { Screening lendoscopic } \\
\text { resection) }\end{array}$ & 17 & Lymphoid follicle \\
\hline
\end{tabular}

LLH, localized lymphoid hyperplasia; UC, ulcerative colitis; FOBT, fecal occult blood test; MALT, mucosa-associated lymphoid tissue; SMT, submucosal tumor. 
study. With a medium-term follow-up period, this study provides a unique perspective on the significance and clinical course of these lesions. Finally, there is a limit to generalizing the results obtained from cohorts composed mostly of Asians, because UC and MALT lymphomas exhibit different epidemiological and clinical features depending on the race and environment. However, our study may serve as a basis for follow-up prospective validation studies dealing with more diverse populations.

In conclusion, most LLHs of the rectum incidentally observed on routine colonoscopy in asymptomatic individuals undergo a benign course and are resolved. However, the rectal LLHs in patients with persistent symptom or endoscopic appearances of nodular or SMT-like type may lead to clinically significant disease. Therefore, follow-up endoscopies may be considered with caution in nodular or SMT-like type. In particular, SMT-like LLHs may need to be continuously monitored even if the primary lesion was completely removed.

\section{CONFLICTS OF INTEREST}

No potential conflict of interest relevant to this article was reported.

\section{AUTHOR CONTRIBUTIONS}

Conceptualization: E.R.K. Methodology: J.T.H., E.R.K., S.W.P. Formal analysis: S.W.P., J.W.K. Project administration: J.T.H. Visualization: J.W.K., S.W.P. Writing - original draft: J.T.H., S.W.P. Writing - review and editing: S.N.H., Y.H.K., D.K.C., E.R.K. Pathology review: J.H.C. Approval of final manuscript: all authors.

\section{ORCID}

\begin{tabular}{ll} 
Ji Taek Hong & https://orcid.org/0000-0002-6310-2958 \\
Eun Ran Kim & https://orcid.org/0000-0002-0495-2565 \\
Sung-Wook Park & https://orcid.org/0000-0002-3534-6672 \\
Ji Won Kim & https://orcid.org/0000-0001-8164-3873 \\
Sung Noh Hong & https://orcid.org/0000-0002-4140-3717 \\
Dong Kyung Chang & \\
\multicolumn{1}{l}{ https://orcid.org/0000-0001-8925-4629 } \\
Young-Ho Kim & https://orcid.org/0000-0003-2760-9556 \\
Jun Hun Cho & https://orcid.org/0000-0002-6089-9340
\end{tabular}

\section{REFERENCES}

1. Riddell RH, Petras RE, Williams GT, Sobin LH. Lymphoproliferative disorders of the intestines. In: Rosai J, Sobin LH, eds. Atlas of tumor pathology: tumor of the intestine. 3rd series, Fascicle 32. Washington, DC: Armed Forces Institute of Pathology, 2003:102-104.

2. Ranchod M, Lewin KJ, Dorfman RF. Lymphoid hyperplasia of the gastrointestinal tract: a study of 26 cases and review of the literature. Am J Surg Pathol 1978;2:383-400.

3. Kealy WF. Colonic lymphoid-glandular complex (microbursa): nature and morphology. J Clin Pathol 1976;29:241244.

4. Cornes JS, Wallace MH, Morson BC. Benign lymphomas of the rectum and anal canal: a study of 100 cases. J Pathol Bacteriol 1961;82:371-382.

5. Kraehenbuhl JP, Neutra MR. Epithelial M cells: differentiation and function. Annu Rev Cell Dev Biol 2000;16:301-332.

6. Kojima M, Itoh H, Motegi A, Sakata N, Masawa N. Localized lymphoid hyperplasia of the rectum resembling polypoid mucosa-associated lymphoid tissue lymphoma: a report of three cases. Pathol Res Pract 2005;201:757-761.

7. Kenney PJ, Koehler RE, Shackelford GD. The clinical significance of large lymphoid follicles of the colon. Radiology 1982;142:41-46.

8. Glick SN, Teplick SK, Ross WM. Colonic lymphoid follicles associated with colonic neoplasms. Radiology 1988;168:603607.

9. Rambaud JC, De Saint-Louvent P, Marti R, et al. Diffuse follicular lymphoid hyperplasia of the small intestine without primary immunoglobulin deficiency. Am J Med 1982;73:125-132.

10. Chiaramonte C, Glick SN. Nodular lymphoid hyperplasia of the small bowel complicated by jejunal lymphoma in a patient with common variable immune deficiency syndrome. AJR Am J Roentgenol 1994;163:1118-1119.

11. Ryan JC. Premalignant conditions of the small intestine. Semin Gastrointest Dis 1996;7:88-93.

12. Castellano G, Moreno D, Galvao O, et al. Malignant lymphoma of jejunum with common variable hypogammaglobulinemia and diffuse nodular hyperplasia of the small intestine. A case study and literature review. J Clin Gastroenterol 1992;15:128-135.

13. Harris M, Blewitt RW, Davies VJ, Steward WP. High-grade non-Hodgkin's lymphoma complicating polypoid nodular lymphoid hyperplasia and multiple lymphomatous polyposis of the intestine. Histopathology 1989;15:339-350.

14. Kahn LB, Novis BH. Nodular lymphoid hyperplasia of the small bowel associated with primary small bowel reticulum cell lymphoma. Cancer 1974;33:837-844.

15. Lamers CB, Wagener T, Assmann KJ, van Tongeren JH. Jeju- 
nal lymphoma in a patient with primary adult-onset hypogammaglobulinemia and nodular lymphoid hyperplasia of the small intestine. Dig Dis Sci 1980;25:553-557.

16. Aguilar FP, Alfonso V, Rivas S, López Aldeguer J, Portilla J, Berenguer J. Jejunal malignant lymphoma in a patient with adult-onset hypo-gamma-globulinemia and nodular lymphoid hyperplasia of the small bowel. Am J Gastroenterol 1987;82:472-475.

17. Gonzalez-Vitale JC, Gomez LG, Goldblum RM, Goldman AS, Patterson M. Immunoblastic lymphoma of small intestine complicating late-onset immunodeficiency. Cancer 1982;49:445-449.

18. Durham JC, Stephens DS, Rimland D, Nassar VH, Spira TJ. Common variable hypogammaglobulinemia complicated by an unusual T-suppressor/cytotoxic cell lymphoma. Cancer 1987;59:271-276.

19. Matuchansky C, Morichau-Beauchant M, Touchard G, et al. Nodular lymphoid hyperplasia of the small bowel associated with primary jejunal malignant lymphoma. Evidence favoring a cytogenetic relationship. Gastroenterology 1980;78:1587-1592.

20. Schaefer PS, Friedman AC. Nodular lymphoid hyperplasia of the small intestine with Burkitt's lymphoma and dysgammaglobulinemia. Gastrointest Radiol 1981;6:325-328.

21. Bayraktar Y, Ersoy O, Sokmensuer C. The findings of capsule endoscopy in patients with common variable immunodeficiency syndrome. Hepatogastroenterology 2007;54:10341037.

22. Hong JB, Kim HW, Kang DH, et al. Rectal tonsil: a case report and literature review. World J Gastroenterol 2015;21:2563-2567.

23. Schwartz DC, Cole CE, Sun Y, Jacoby RF. Diffuse nodular lymphoid hyperplasia of the colon: polyposis syndrome or normal variant? Gastrointest Endosc 2003;58:630-632.

24. Garg V, Lipka S, Rizvon K, Singh J, Rashid S, Mustacchia P. Diffuse nodular lymphoid hyperplasia of intestine in selective IgG 2 subclass deficiency, autoimmune thyroiditis, and autoimmune hemolytic anemia: case report and literature review. J Gastrointestin Liver Dis 2012;21:431-434.

25. Farris AB, Lauwers GY, Ferry JA, Zukerberg LR. The rectal tonsil: a reactive lymphoid proliferation that may mimic lymphoma. Am J Surg Pathol 2008;32:1075-1079.

26. Kojima M, Iijima M, Shimizu K, Hoshi K. Localized lymphoid hyperplasia of the rectum representing progressive transformation of the germinal center: a report of two cases. APMIS 2007;115:1432-1436.

27. Eire PF, Victoria RF, Castañón AI, Arias MP, Carril AL, Burriel JI. The rectal tonsil in children: a reactive lymphoid proliferation that may mimic a lymphoma. Indian J Gastroenterol 2011;30:282-283.

28. Homan M, Volavšek M. Rectal tonsil. J Pediatr Gastroenterol Nutr 2012;54:575.

29. Grube-Pagola P, Canales-Kay A, Meixueiro-Daza A, RemesTroche JM. Rectal tonsil associated with Epstein-Barr virus. Endoscopy 2012;44 Suppl 2 UCTN:E388-E389.

30. Kojima M, Nakamura $\mathrm{N}$, Itoh $\mathrm{H}$, et al. Histological variety of localized lymphoid hyperplasia of the large intestine: histopathological, immunohistochemical and genotypic findings of 16 cases. J Clin Exp Hematop 2009;49:15-21.

31. de Lange KM, Barrett JC. Understanding inflammatory bowel disease via immunogenetics. J Autoimmun 2015;64:91100.

32. Lok KH, Hung HG, $\mathrm{Ng} \mathrm{CH}$, et al. Epidemiology and clinical characteristics of ulcerative colitis in Chinese population: experience from a single center in Hong Kong. J Gastroenterol Hepatol 2008;23:406-410.

33. Ng SC, Tang W, Ching JY, et al. Incidence and phenotype of inflammatory bowel disease based on results from the Asiapacific Crohn's and colitis epidemiology study. Gastroenterology 2013;145:158-165.

34. Takehara M, Muguruma N, Kitamura S, et al. Twin rectal tonsils mimicking carcinoid or mucosa-associated lymphoid tissue lymphoma. Clin Endosc 2017;50:500-503. 